Supporting Information

\title{
Cascade Ring Opening/Ring Closing Metathesis Polymerization of a Monomer Containing a Norbornene and a Cyclohexene Ring
}

Mohammad Yasir and Andreas F. M. Kilbinger*

Department of Chemistry, University of Fribourg, Chemin du Musée 9, CH-1700 Fribourg, Switzerland

*andreas.kilbinger@unifr.ch

\section{Table of Contents}

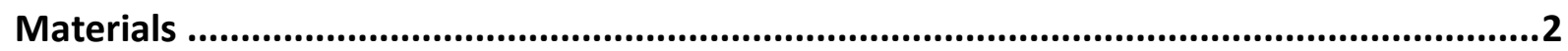

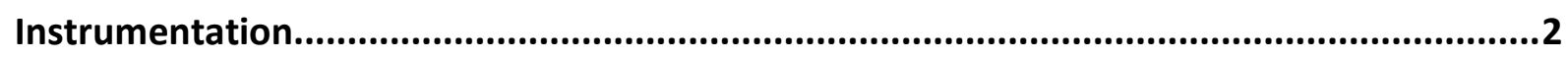

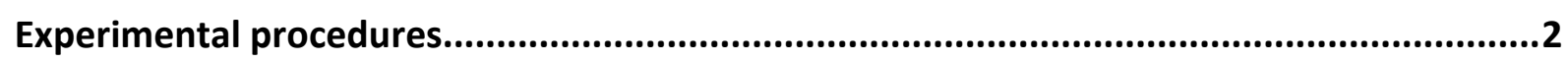

Synthesis of 7-(cyclohex-2-en-1-yloxy)bicyclo[2.2.1]hept-2-ene (M):..................................... 2

General procedure for cascade ring opening/ring closing metathesis (RO/RCM) polymerization: 3

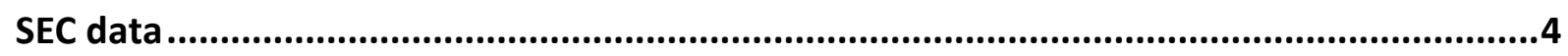

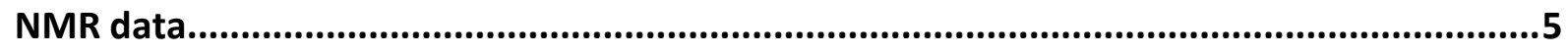

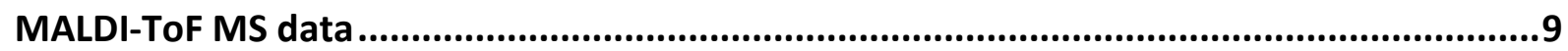

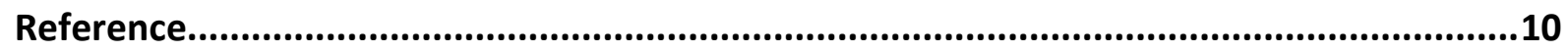




\section{Materials}

Grubbs' first (G1) and third generation catalyst (G3), 3-bromocyclohexene, sodium hydride, ethyl vinyl ether and all other starting materials were purchased from Sigma-Aldrich unless stated otherwise and used without further purification. Bicyclo[2.2.1]hept-2-en-7-ol was synthesized as reported previously. ${ }^{1}$ Deuterated solvents $\left(\mathrm{CD}_{2} \mathrm{Cl}_{2}\right.$ and $\left.\mathrm{CDCl}_{3}\right)$ were purchased from Cambridge Isotope Laboratories, Inc. Deuterated dichloromethane was degassed by 3 successive freeze-vacuum-thaw cycles immediately before use.

\section{Instrumentation}

Relative molecular weights and molecular weight distributions were measured by size exclusion chromatography (SEC) using tetrahydrofuran (THF) as eluent with a flow rate of $1 \mathrm{~mL} / \mathrm{min}$. The system was calibrated with polystyrene standards in a range from $10^{3}$ to $3 \times 10^{5} \mathrm{Da}$. The instrument is an automated Viscotek GPCmax VE-2001 with a set of two Viscotek T6000M linear columns (300x8 mm, $5 \mu \mathrm{m}$ particle size). Signal detection occurred by use of a Viscotek VE 3580 refractive index (RI) detector. 1D-NMR, COSY and ROESY spectra were recorded on a Bruker Avance III 300/400 MHz NMR spectrometer ( ${ }^{1} \mathrm{H}$ NMR: $300 / 400 \mathrm{MHz} ;{ }^{13} \mathrm{C}$ NMR: 75/101 MHz). NMR signals were referenced internally to residual solvent signals. Matrix assisted laser desorption ionization time of flight mass spectrometry (MALDI-ToF MS) was conducted on a Bruker UltrafleXtreme instrument using 2-[(2E)-3-(4tertbutylphenyl)-2-methylprop-2-enylidene] malononitrile (DCTB) as the matrix and silver trifluoroacetate as the ionizing salt. Electron ionization mass spectrum (EI-MS) was run on a gas chromatography-mass spectrometry (GC-MS) instrument (Thermo Scientific DSQ II Series Single GC/MS with Trace GC Ultra gas chromatograph and Zebron capillary GC column (ZB-5MS, $0.25 \mu \mathrm{m}$, 30x $0.25 \mathrm{~mm})$ ).

\section{Experimental procedures}

\section{Synthesis of 7-(cyclohex-2-en-1-yloxy)bicyclo[2.2.1] hept-2-ene (M):}

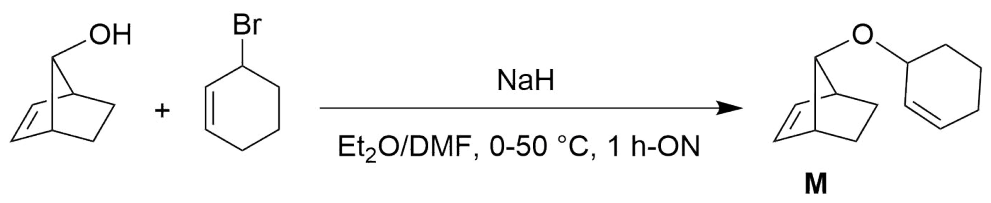

$\mathrm{NaH}$ (60\% dispersion in oil, $0.196 \mathrm{~g}, 4.902 \mathrm{mmol}, 1.2 \mathrm{eq})$ was suspended in dry $\mathrm{Et}_{2} \mathrm{O}(10 \mathrm{~mL})$. After cooling to $0{ }^{\circ} \mathrm{C}$, a solution of bicyclo[2.2.1] hept-2-en-7-ol $(0.45 \mathrm{~g}, 4.085 \mathrm{mmol}, 1 \mathrm{eq})$ in dry $\mathrm{Et}_{2} \mathrm{O}(5 \mathrm{~mL})$ was added over $15 \mathrm{~min}$ and the suspension stirred at $0{ }^{\circ} \mathrm{C}$ for 1 hour. Dry $\mathrm{N}, \mathrm{N}$-dimethylformamide (DMF) ( $3 \mathrm{~mL}$ ) was then added in one portion, followed by dropwise addition of 3-bromocyclohexene $(0.921 \mathrm{~g}, 5.719 \mathrm{mmol}, 1.4 \mathrm{eq})$ in dry $\mathrm{Et}_{2} \mathrm{O}(5 \mathrm{~mL})$ over a period of $30 \mathrm{~min}$. The temperature of the reaction mixture was raised to $50{ }^{\circ} \mathrm{C}$. The suspension was stirred overnight at this temperature. The reaction was then terminated with water and extracted with ethyl acetate $(3 \times 25 \mathrm{~mL})$. The organic layers were combined, dried over anhydrous $\mathrm{MgSO}_{4}$ and concentrated in vacuo. The crude product was purified by column chromatography ( $\mathrm{Et}_{2} \mathrm{O}$ :pentane $\left.1: 49\right)$ to give the product $(0.25 \mathrm{~g}, 32 \%$ yield) as a yellowish oil. ${ }^{1} \mathrm{H}$ NMR $\left(300 \mathrm{MHz}, \mathrm{CDCl}_{3}\right): \delta=5.92-6.03(\mathrm{~m}, 2 \mathrm{H}), 5.77-5.87(\mathrm{~m}, 1 \mathrm{H}), 5.64-5.75(\mathrm{~m}, 1$ H), $3.80-3.90(\mathrm{~m}, 1 \mathrm{H}), 3.36(\mathrm{~s}, 1 \mathrm{H}), 2.58-2.69(\mathrm{~m}, 2 \mathrm{H}), 1.88-2.12(\mathrm{~m}, 2 \mathrm{H}), 1.68-1.88(\mathrm{~m}, 4 \mathrm{H}), 1.46$ - $1.68(\mathrm{~m}, 2 \mathrm{H}), 0.88-1.02 \mathrm{ppm}(\mathrm{m}, 2 \mathrm{H}) .{ }^{13} \mathrm{C} \mathrm{NMR}\left(75 \mathrm{MHz}, \mathrm{CDCl}_{3}\right): \delta=134.3,134.1,130.4,128.6,87.4$, 70.9, 44.3, 43.9, 29.2, 25.1, 22.0, 21.8, 19.5 ppm. El-MS m/z [M]: calculated 190.14, found 190.18. 


\section{General procedure for cascade ring opening/ring closing metathesis (RO/RCM)}

\section{polymerization:}

A solution of metathesis catalyst G1/G3 (4 mg, $0.00486 / 0.00452 \mathrm{mmol}, 1$ eq) and 1,3,5trimethoxybenzene ( $2 \mathrm{mg}$ ) (NMR standard) in a given amount of dry and degassed $\mathrm{CD}_{2} \mathrm{Cl}_{2}$ was prepared in a vial under argon. The polymerization was started by the addition of a desired amount of the monomer $\mathrm{M}$ after dissolving in a given amount of dry and degassed $\mathrm{CD}_{2} \mathrm{Cl}_{2}$ into this vial at room temperature. If required, the reaction was terminated with $0.1 \mathrm{~mL}(215 \mathrm{eq})$ of ethyl vinyl ether after the given time. The whole reaction mixture was transferred to an NMR tube under argon and the conversion was followed by ${ }^{1} \mathrm{H}$ NMR spectroscopy. The polymer was precipitated in cold methanol, if needed.

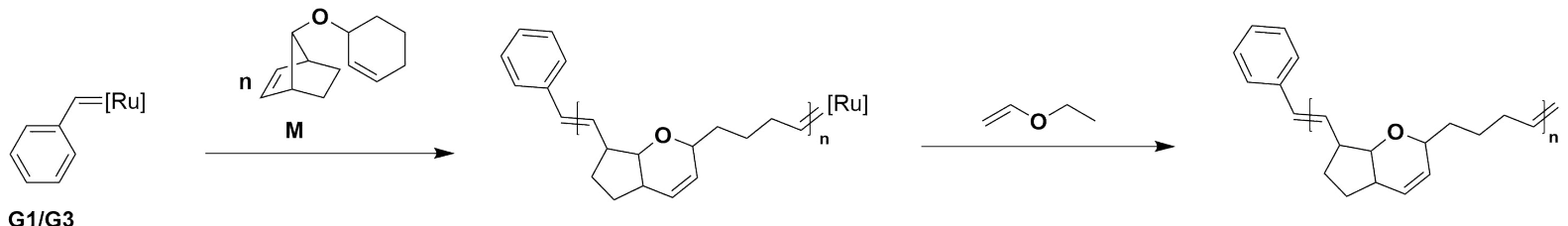

Table S1. Polymerization time optimization and synthesis of different molecular weight polymers by changing monomer $\mathrm{M}$ to $\mathrm{G} 1 / \mathrm{G} 3$ ratio.

\begin{tabular}{|c|c|c|c|c|c|c|c|c|}
\hline entry & $\begin{array}{c}\mathbf{M}\left(\mathrm{CD}_{2} \mathrm{Cl}_{2}\right): \mathbf{G 1} / \mathbf{G 3} \\
\left(\mathrm{CD}_{2} \mathrm{Cl}_{2}\right)\end{array}$ & time & conv. $^{\mathrm{a}}$ & $\begin{array}{c}\mathrm{M}_{n}, \\
\text { theo }^{b}\end{array}$ & $\begin{array}{c}\mathrm{M}_{\mathrm{n}}, \\
\text { found }^{\mathrm{c}}\end{array}$ & $\begin{array}{c}\text { PDI } \\
(\bigoplus)^{\mathrm{c}}\end{array}$ & yield & polymer \\
\hline $1^{*}$ & $15(0.6 \mathrm{~mL}): 1 /-(0.3 \mathrm{~mL})$ & $12 \mathrm{~min}$ & $100 \%$ & - & - & - & - & - \\
\hline 2 & $15(0.6 \mathrm{~mL}): 1 /-(0.3 \mathrm{~mL})$ & $4 \mathrm{~min}$ & $97 \%$ & - & - & - & - & - \\
\hline 3 & $15(0.6 \mathrm{~mL}): 1 /-(0.3 \mathrm{~mL})$ & $6 \mathrm{~min}$ & $100 \%$ & $3.7 \mathrm{kDa}$ & $4.2 \mathrm{kDa}$ & 1.35 & $85 \%$ & $\mathrm{P} 1$ \\
\hline 4 & $20(0.8 \mathrm{~mL}): 1 /-(0.4 \mathrm{~mL})$ & $8 \mathrm{~min}$ & $100 \%$ & $4.9 \mathrm{kDa}$ & $5.3 \mathrm{kDa}$ & 1.42 & $88 \%$ & $\mathrm{P} 2$ \\
\hline 5 & $25(1 \mathrm{~mL}): 1 /-(0.5 \mathrm{~mL})$ & $10 \mathrm{~min}$ & $100 \%$ & $6.1 \mathrm{kDa}$ & $6.3 \mathrm{kDa}$ & 1.40 & $90 \%$ & $\mathrm{P} 3$ \\
\hline 6 & $15(0.6 \mathrm{~mL}):-/ 1(0.3 \mathrm{~mL})$ & $1 \mathrm{~min}$ & $100 \%$ & $2.9 \mathrm{kDa}$ & $2.9 \mathrm{kDa}$ & 1.09 & $86 \%$ & $\mathrm{P} 4$ \\
\hline $7^{\mathrm{d}}$ & $15(0.6 \mathrm{~mL}): 1 /-(0.3 \mathrm{~mL})$ & $1 \mathrm{~h} 48 \mathrm{~min}$ & $100 \%$ & $3.7 \mathrm{kDa}$ & $3.3 \mathrm{kDa}$ & 1.49 & $84 \%$ & $\mathrm{P} 5$ \\
\hline
\end{tabular}

${ }^{\mathrm{a} C o n v e r s i o n}$ was determined via ${ }^{1} \mathrm{H}$ NMR spectroscopy. ${ }^{\mathrm{b}}$ Theoretical molecular weight was calculated according to $72 \%$ initiation efficiency of G1 except for entry 6 (in case of G3, as it is known for complete initiation). "Molecular weight and polydispersity index (PDI ( $\boxminus)$ ) were determined using THF SEC. *The polymerization reaction was not terminated with ethyl vinyl ether. ${ }^{\mathrm{d}}$ This experiment was done to see if the dispersity increases over time after the consumption of the monomer (see entry 3 and 7). The broadening of dispersity can be attributed to both inter and intramolecular chain-transfer events while lowering of the molecular weight is caused by intramolecular chain-transfer events. 

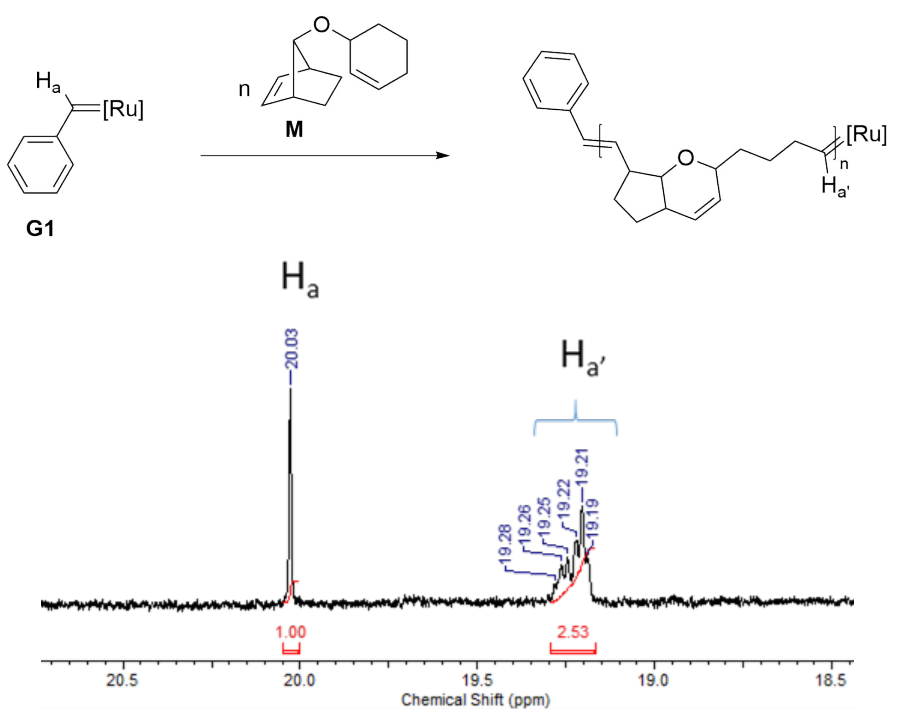

Figure S1. ${ }^{1} \mathrm{H}$ NMR spectrum $\left(300 \mathrm{MHz}, \mathrm{CD}_{2} \mathrm{Cl}_{2}\right)$ showing the $72 \%$ initiation efficiency of $\mathrm{G} 1$ in a polymerization reaction (entry 1 , Table $\mathrm{S} 1$ ).

\section{SEC data}

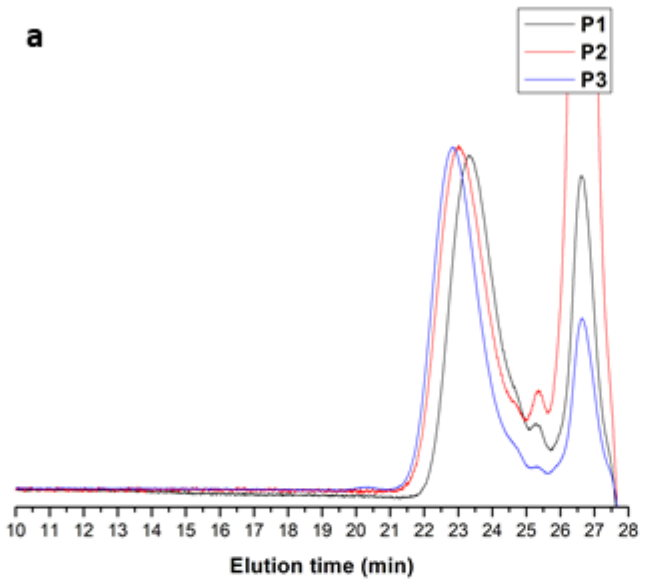

b
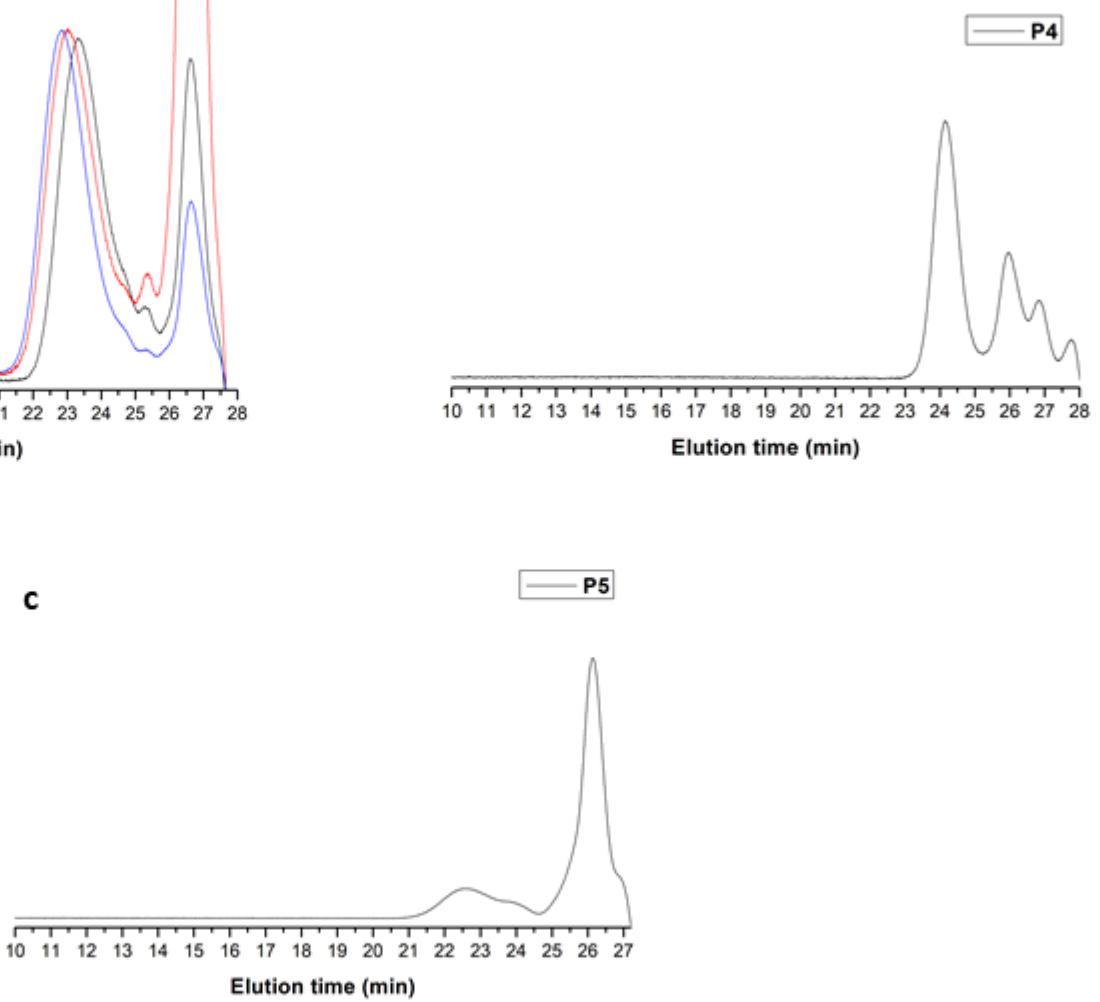

Figure S2. SEC (THF) traces of polymers (a) P1-P3, (b) P4 and (c) P5. SEC traces of P1-P3 are normalized. 


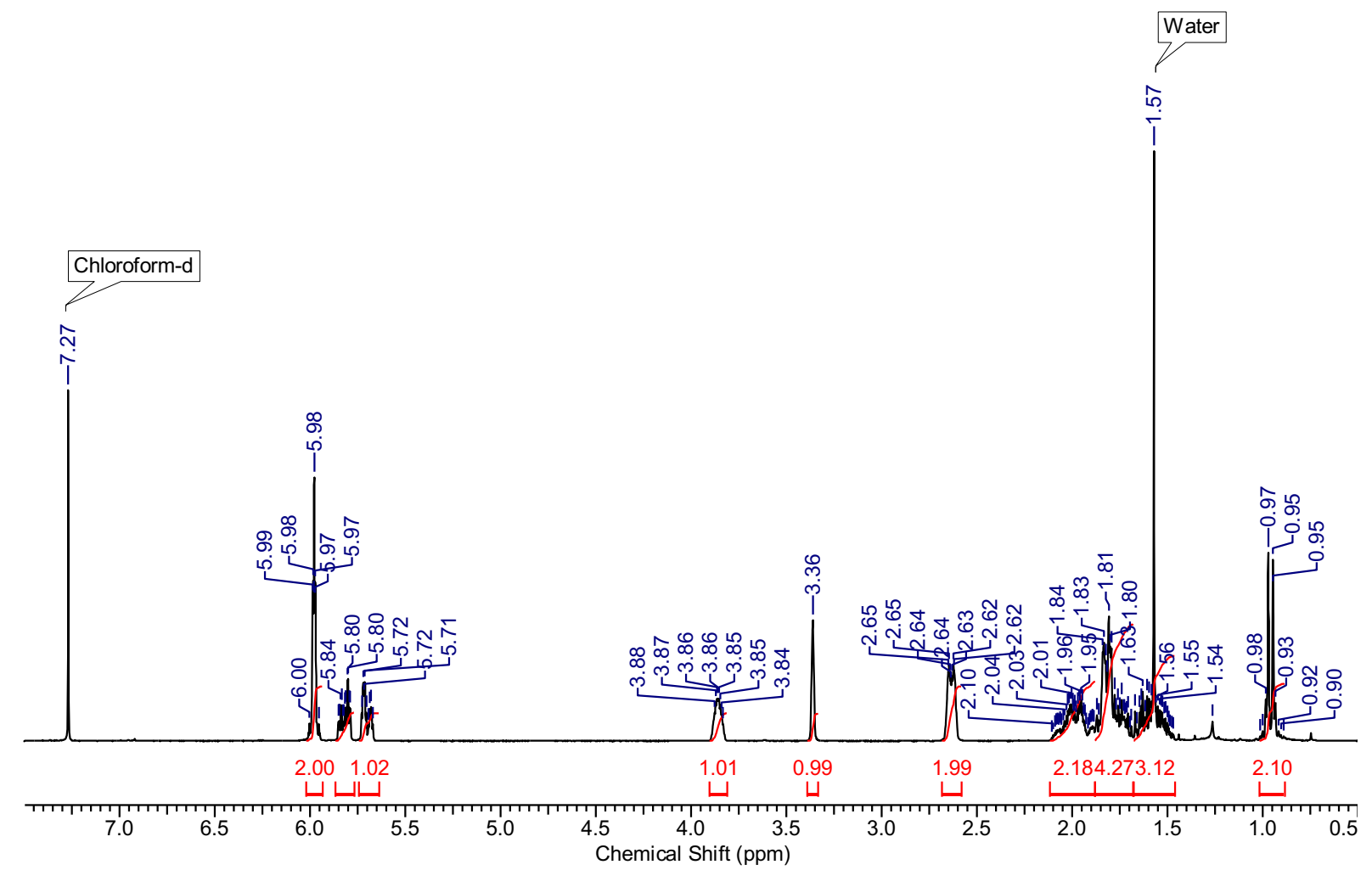

Figure S3. ${ }^{1} \mathrm{H}$ NMR spectrum $\left(300 \mathrm{MHz}, \mathrm{CDCl}_{3}\right)$ of $\mathrm{M}$.

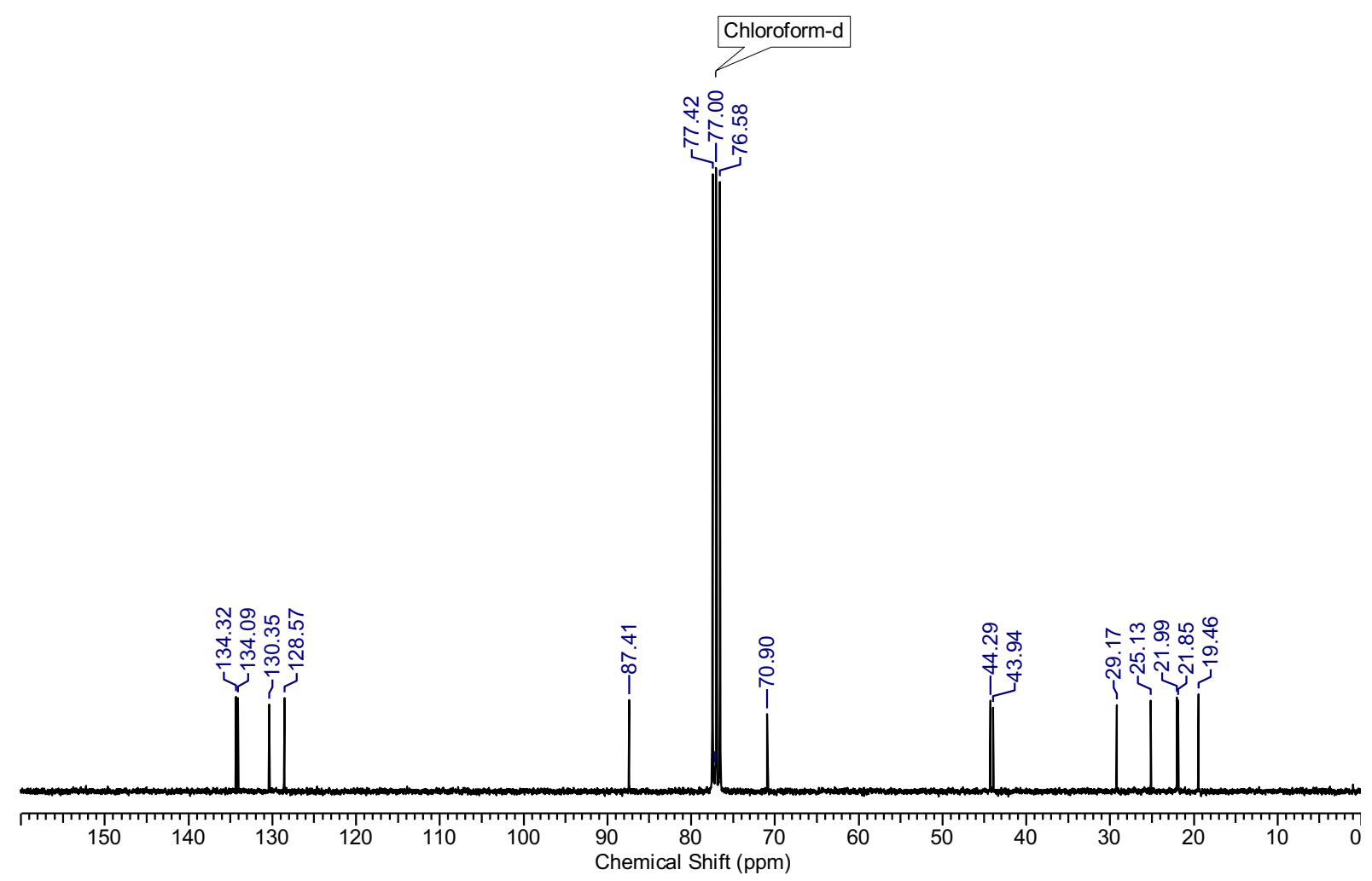

Figure S4. ${ }^{13} \mathrm{C}$ NMR spectrum $\left(75 \mathrm{MHz}, \mathrm{CDCl}_{3}\right)$ of $\mathrm{M}$. 


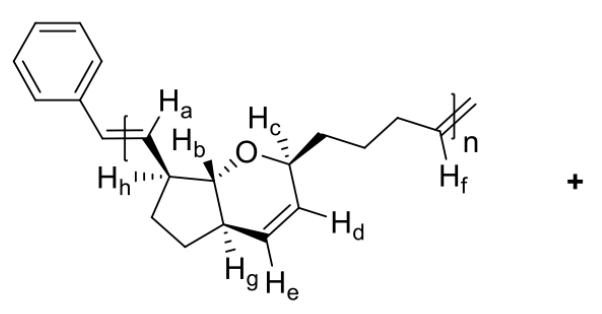

$P 1_{\text {trans }}$

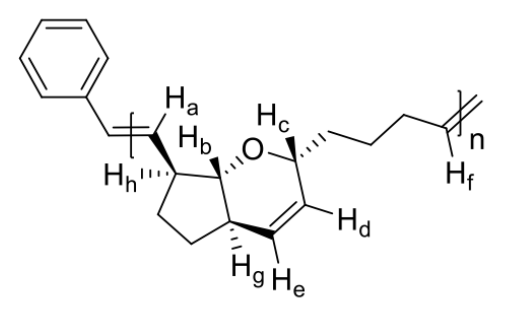

P1 $1_{\text {cis }}$

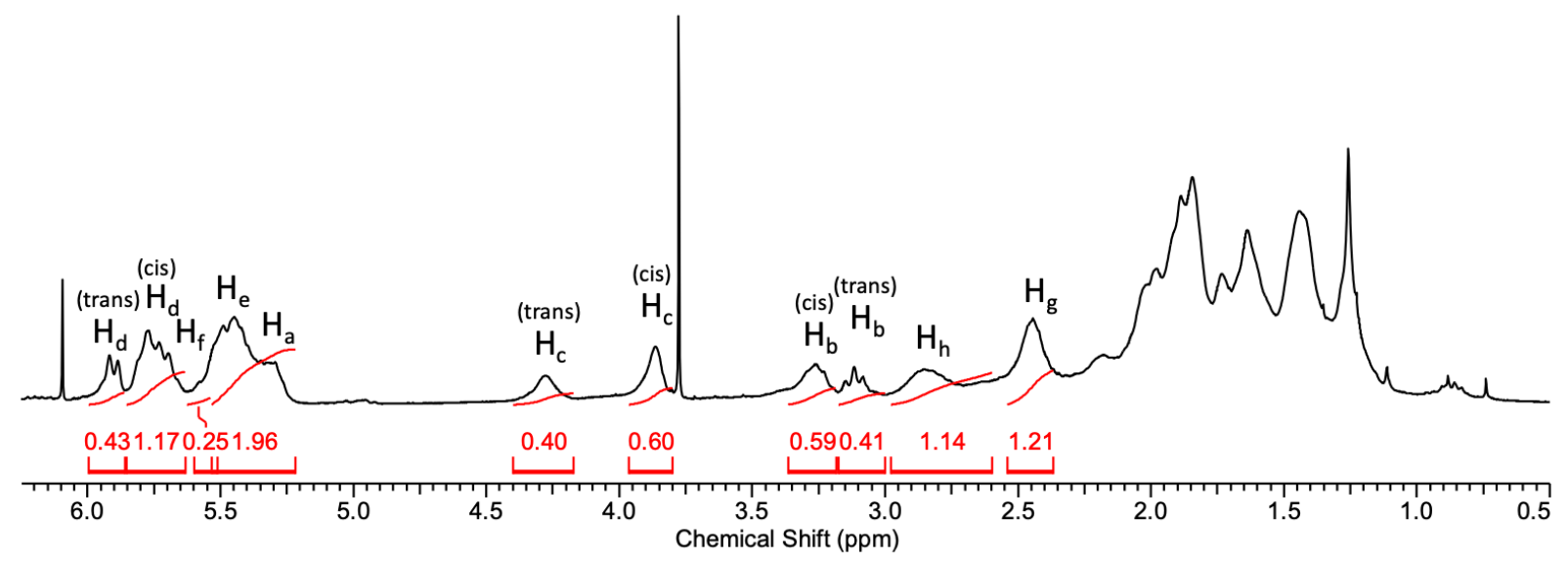

Figure S5. ${ }^{1} \mathrm{H}$ NMR spectrum ( $400 \mathrm{MHz}, \mathrm{CDCl}_{3}$ ) of $\mathrm{P} 1$. Signals at 3.78 and $6.09 \mathrm{ppm}$ belong to the internal standard (1,3,5 trimethoxybenzene) present in the residual amount. 


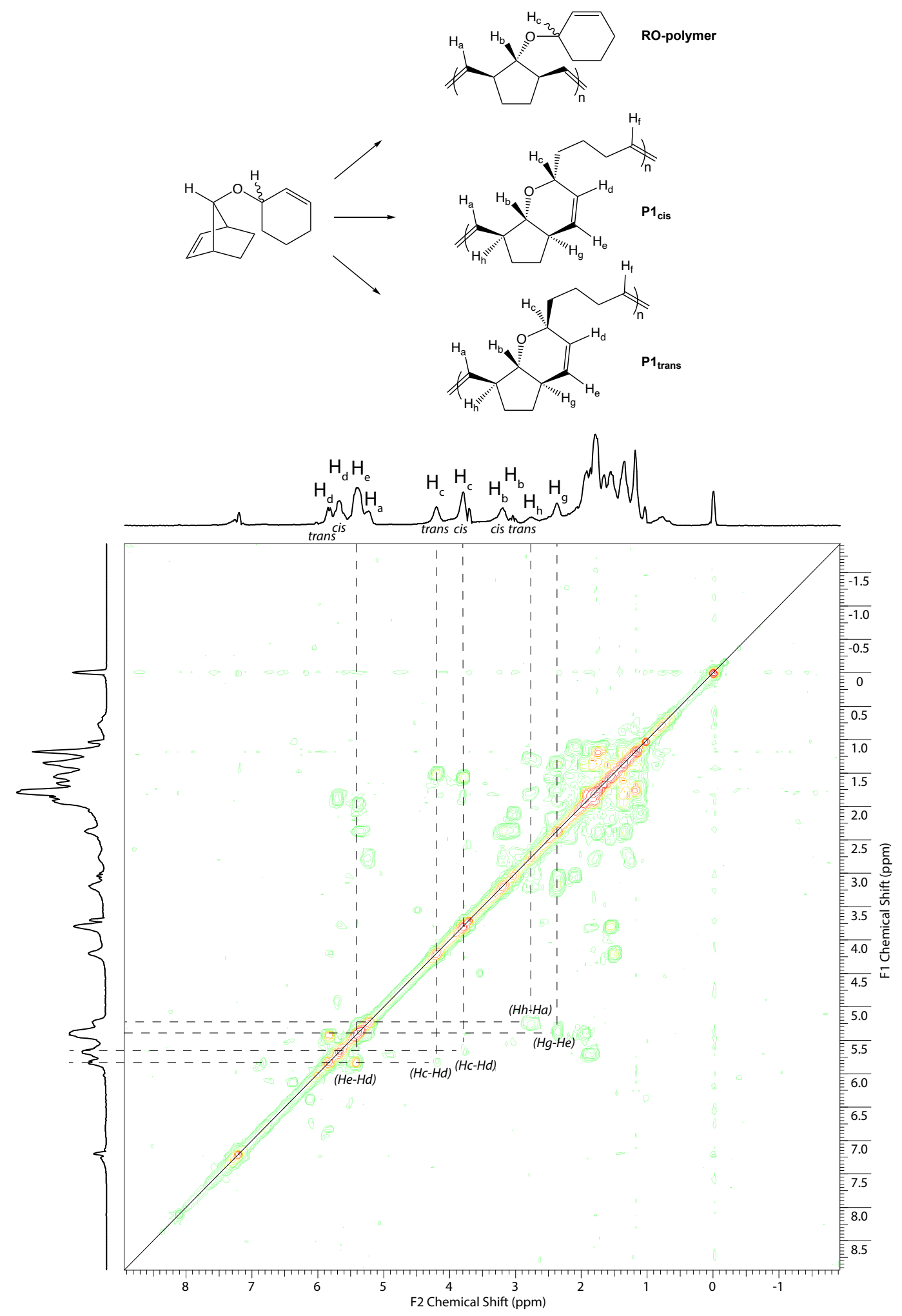

Figure S6. ${ }^{1} \mathrm{H}-{ }^{1} \mathrm{H}$ COSY spectrum $\left(400 \mathrm{MHz}, \mathrm{CDCl}_{3}\right)$ of $\mathrm{P} 1$. The peak assignment suggests that two types of repeat units are present, $\mathrm{P} 1_{\text {cis }}$ and $\mathrm{P} 1_{\text {trans. }}$. This can only be explained by excluding the hypothetical structure RO-polymer which would give rise to only one peak each for $\mathrm{H}_{b}$ and $\mathrm{H}_{c}$. 


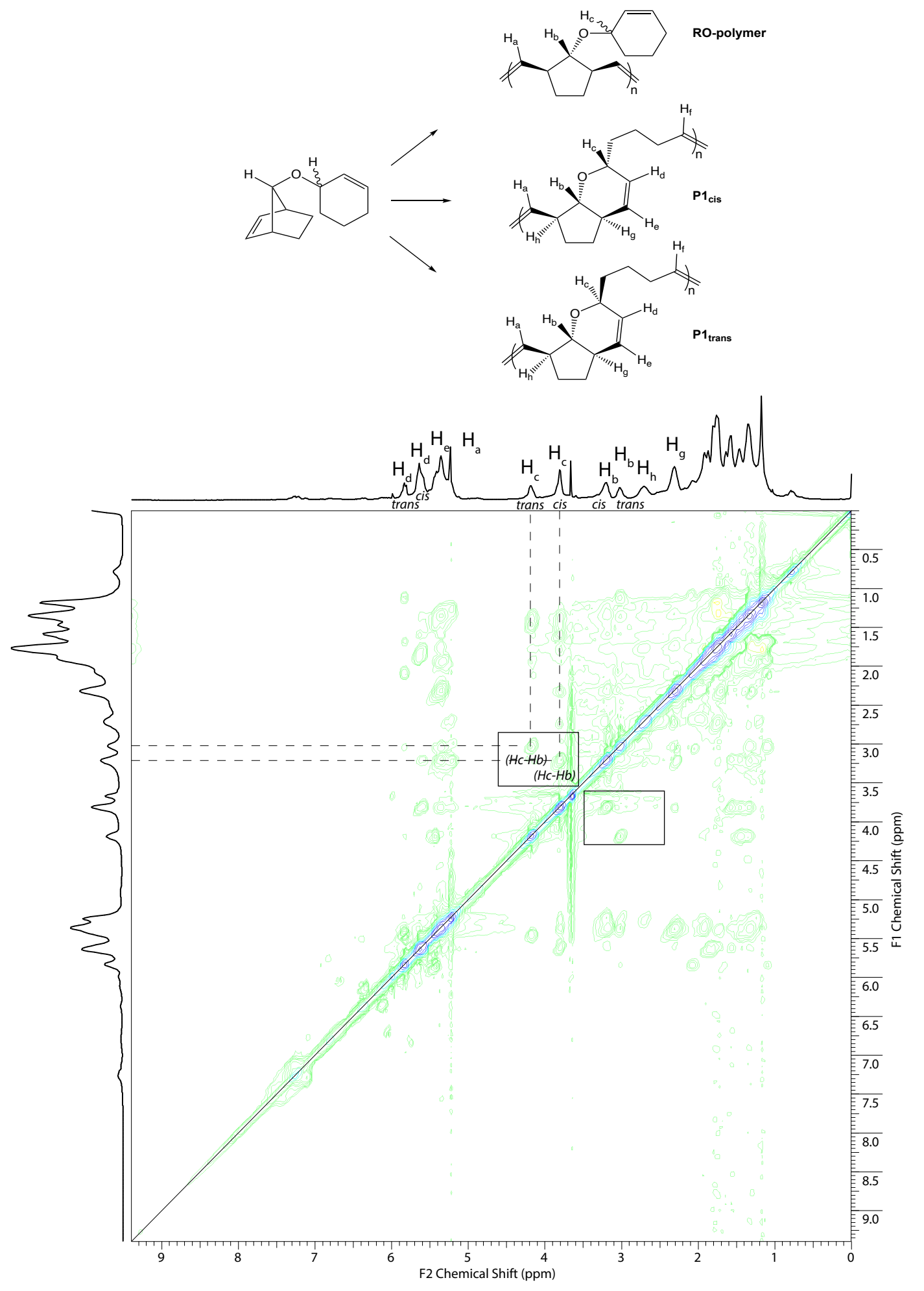

Figure S7. ${ }^{1} \mathrm{H}-{ }^{1} \mathrm{H}$ ROESY spectrum $\left(400 \mathrm{MHz}, \mathrm{CD}_{2} \mathrm{Cl}_{2}\right)$ of $\mathrm{P} 1$. The coupling between $\mathrm{H}_{\mathrm{b}}$ and $\mathrm{H}_{\mathrm{c}}$ protons agrees with the peak assignment above, shows the close proximity of the $H_{b}$ and $H_{c}$ protons and suggests the presence of two types of repeat units which are denoted $\mathrm{P} 1_{\text {cis }}$ and $\mathrm{P} 1_{\text {trans. }}$. The hypothetical polymer repeat unit where only the norbornene is ring opened (RO-polymer) would not give rise to two sets of $\mathrm{H}_{\mathrm{b}}$ and $\mathrm{H}_{\mathrm{c}}$ signals and is, therefore, excluded. 


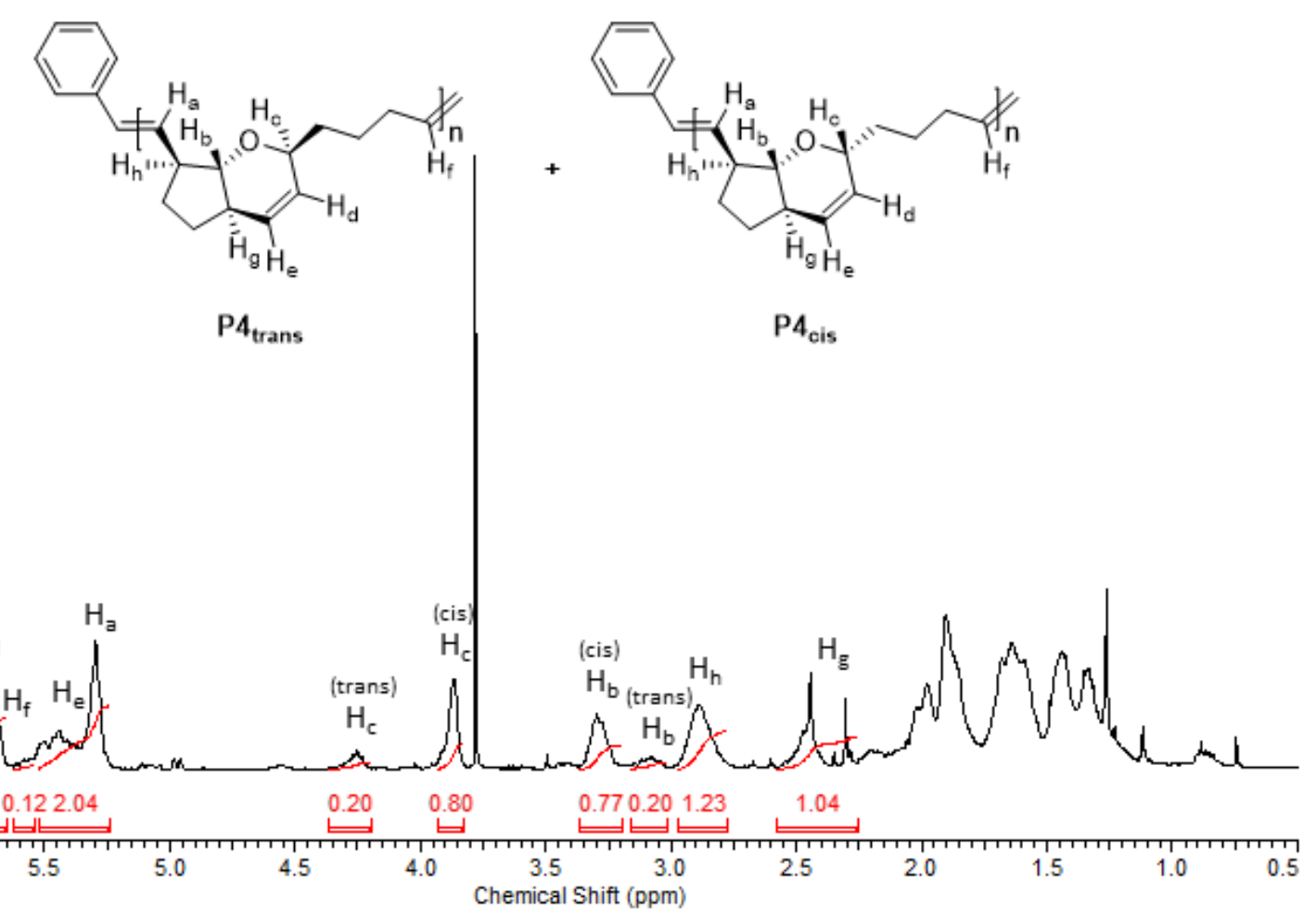

Figure S8. ${ }^{1} \mathrm{H}$ NMR spectrum $\left(400 \mathrm{MHz}, \mathrm{CDCl}_{3}\right)$ of $\mathrm{P} 4$. Signals at 3.78 and $6.09 \mathrm{ppm}$ belong to the internal standard $(1,3,5$ trimethoxybenzene) present in the residual amount.

\section{MALDI-ToF MS data}

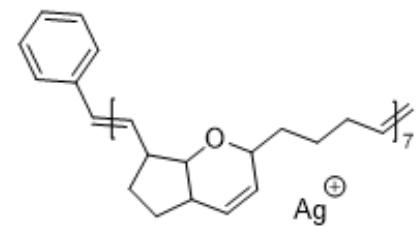

Exact mass: 1541.92

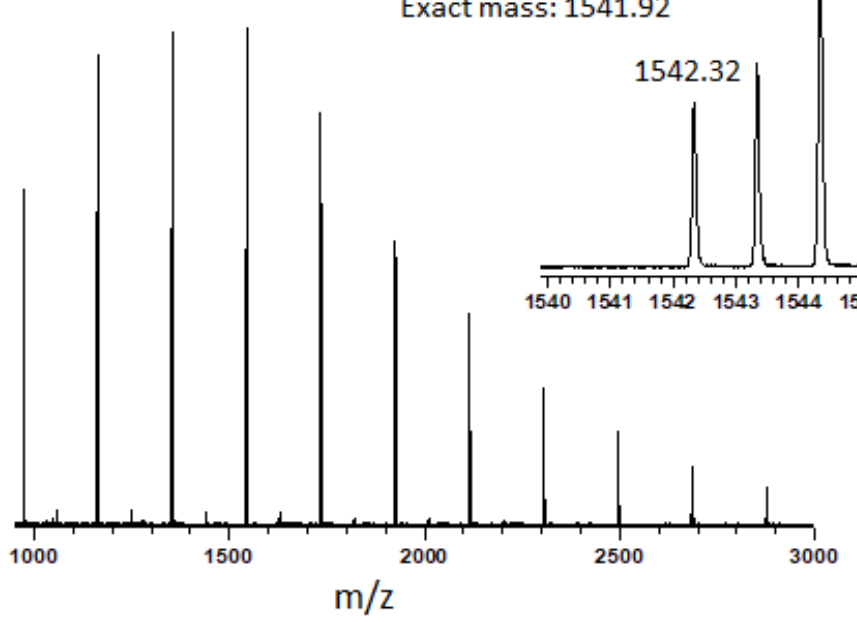

Figure S9. MALDI-ToF mass spectrum of P1. 


\section{Reference}

1. Yasir, M.; Liu, P.; Tennie, I. K.; Kilbinger, A. F. M. Catalytic living ring-opening metathesis polymerization with Grubbs' second- and third-generation catalysts. Nat. Chem. 2019, 11, 488494. 